\title{
Study on Umbilical Cord-Matrix Stem Cells Transplantation for Treatment of Acute Traumatic Brain Injury in Rats
}

\author{
Yanmin WANG ${ }^{*}$, Dingwei PENG*2,3, Xiping Yang ${ }^{* 2}$, Pengfei HUANG ${ }^{*}$, Haoyi YE*4, Yuetong HUI ${ }^{4}$, Xi WANG ${ }^{5}$, \\ Wentao SUN 1 , Huancheng WU1', Shijun ZHANG ${ }^{1}$, Lei WANG ${ }^{6}$, Hong SHA ${ }^{6}$, Chongzhi SHANG ${ }^{2}$, Huajiang DONG ${ }^{4}$, \\ Qunliang HU1
}

${ }^{1}$ Tianjin Beichen Hospital ,Tianjin, China

${ }^{2}$ Specialty Medical Center of Chinese People's Armed Police Forces, Department of Neurosurgery, Tianjin, China

${ }^{3}$ Neural Restoration Key Laboratory of Tianjin, Tianjin, China

${ }^{4}$ Logistics University of Chinese People's Armed Police Forces, Tianjin, China

5The Fifth Brigade of Peking Headquarters of Chinese People's Armed Police Forces, Peking, China

${ }^{6}$ Institute of Biomedical Engineering, Chinese Academy of Medical Sciences \& Peking Union Medical College, Tianjin, China

${ }^{\star}$ These authors are the co-first authors.

Corresponding author: Lei WANG leiwang2006163@163.com; Huajiang DONG dhj_424@163.com; Qunliang HU hjhhql@sina.com

\section{ABSTRACT}

AIM: To evaluate the effect of umbilical cord derived mesenchymal stem cells (UC-MSCs) transplantation on traumatic brain injury (TBI).

MATERIAL and METHODS: UC-MSCs were isolated from human umbilical cord and TBI rat model was constructed. 30 male SD rats were randomly divided into 3 groups: control group, TBI group and MSCs transplantation group. Rats in MSCs group received the injection of a total of $1.5 \times 106 \mathrm{MSCs}(25 \mu \mathrm{l})$ via ventricle at operated ventricular coordinates $(0$ at bregma, $1.5 \mathrm{~mm}$ at lateral, 1.1 $\mathrm{mm}$ at behind, $4.5 \mathrm{~mm}$ in depth).

RESULTS: $80 \%$ confluence of cells was formed from tissue at day 10 and the amount of CD90, CD73, CD105 positive cells increased correspondingly. In TBI model, clear hyperemia, edema and obvious infiltration of inflammatory cells in brain tissue were found. However, the manifestations were alleviated after the treatment of MSCs. In MSCs group, GFP in the brain tissue and the area around the vessels were found after the injection, while the expression levels of micro-vessel density (MVD), brain-derived neurotrophic factor (BDNF) and glial fibrillary acidic protein (GFAP) were elevated.

CONCLUSION: UC-MSCs transplantation for treatment of acute TBI could effectively reduce the injury and improve the vascular reconstruction.

KEYWORDS: Umbilical cord, Mesenchymal stem cells, Trauma brain injury

ABBREVIATIONS: BDNF: Brain-derived neurotrophic factor, GFAP: Glial fibrillary acidic protein, MSCs: Mesenchymal stem cells, MVD: Micro-vessel density, TBI: Traumatic brain injury, UC-MSCs: Umbilical cord derived mesenchymal stem cells.

Yanmin WANG (1): 0000-0002-5102-4497

Dingwei PENG : : 0000-0001-8112-5902

Xiping YANG (1): 0000-0003-3583-813X

Pengfei HUANG (1) : 0000-0002-5371-3237

Haoyi YE (1): 0000-0002-7655-8006

$\begin{array}{ll}\text { Yuetong HUI } & \text { (1) : }: 0000-0001-7428-5481 \\ \text { Xi WANG } & \text { (D) : 0000-0003-1881-0741 } \\ \text { Wentao SUN } & \text { (D) : 0000-0002-7126-7760 } \\ \text { Huancheng WU } & \text { (D) : 0000-0002-5455-8646 } \\ \text { Shijun ZHANG } & \text { (1) : } 0000-0003-1215-8078\end{array}$

Lei WANG

(1) : 0000-0002-2931-8317

Hong SHA

(1) : 0000-0003-2024-2229

Chongzhi SHANG (D): 0000-0001-7207-9115

Huajiang DONG (1): :0000-0002-4141-3077

Qunliang HU (1) : 0000-0003-1508-9346 


\section{INTRODUCTION}

$\mathrm{T}$ Iraumatic brain injury (TBI) remains as a serious public health problem (21). Tremendous attention has been paid due to its high mortality rate. Traffic accidents are the main cause of TBI. The investigation report of the US National Institutes of Health showed that the cost for a severe brain injury survivor can be more than $\$ 4$ million for careful treatment and care within 5 to 10 years after injury. High death and disability rate caused by TBI bring huge economic burden to the society, the development of effective treatment for TBI patients is thus of great importance. Mesenchymal stem cells (MSCs) are one type of cells which has a remarkable function of self-renewal and multipotential differentiation (6-8). They are abundant in the bone marrow, umbilical cord blood, umbilical cord, systemic connective tissues and organs. As a source of mesenchymal stem cells, the umbilical cord presents an incomparable advantage, and also shows a distinct advantage overthe bone marrow MSCson separation, preparation, storage $(6,14,22,24,26)$. However, studies on stem cell infusion by the infection of pathogenic microorganisms are far fewer than on bone marrow transplantation. Human umbilical cord contains abundant mesenchymal stem cells, which are more primitive than bone marrow MSCs (22). Umbilical cord derived MSCs (UC-MSCs) have strong biological activity and differentiation function, and still maintain strong function after several cell passages and propagation, which provide adequate sources of MSCs for experimental and clinical studies. Compelling reports indicate that using the chemical and neurotrophic factor inducing, UC-MSCs can differentiate into neural stem cells, can also differentiate into oligodendrocyte precursor cells, and secrete a variety of nerve growth factors [ac eg. micro-vessel density (MVD), brain-derived neurotrophic factor (BDNF), glial cell line-derived neurotrophic factor (GDNF)] and promote axonal growth, these cells not only have morphology and phenotype of oligodendrocyte precursor cell, they also play the corresponding function $(4,12,18,19,29,31)$. UCMSCs exhibit particular characteristics of strong proliferation, low immunogenicity, and multi-potential differentiation, all of which contribute to the success of cell transplantation. Those properties are even maintained after a great many of cell passages, leaving UC-MSCs as a fitting candidate for experimental and clinical practice $(5,10,12,24)$. Compelling reports indicated that being induced with the chemical and neurotrophic reagents, UC-MSCs were able to differentiate into neural stem cells, oligodendrocyte precursor cells, and secrete a variety of nerve growth factors MVD, BDNF and GDNF, which promote axonal growth. With the recent development of stem cell technology, we intend to investigate the role of umbilical cord mesenchymal stem cell transplantation for the treatment of acute traumatic brain injury, and to provide a theoretical basis and foundation in the future treatment of acute brain injury.

\section{MATERIAL and METHODS}

\section{Preparation of Human Umbilical Cord Mesenchymal Stem Cells}

The human UC was obtained from woman who gave birth in obstetrics department of affiliated Hospital of Logistics University of Chinese People's Armed Police Forces. After the normal fresh umbilical cord was rinsed with phosphate buffered saline (PBS), the vessels was stripped; The Wharton's jelly was then stripped and was fully shredded into $1 \mathrm{~mm}$ in size; The BioWhittaker ultra CULTURETM cell culture medium (general purpose serum free medium without L-Glutamine Catalog No.:12-725F, Lot No.:0000479259) (Lonza, St. Walkersville, MD21793, USA) was used for mesenchymal stem cells culture and separation in 5\% CO2 incubator at $37^{\circ} \mathrm{C}$. The $4^{\text {th }}$ generation UC-MSCs with cell viability $\geq 90 \%$ was used for our experiment.

\section{Ethic Consideration}

Written informed consent was obtained from woman for the use of the umbilical cord. The study was approved by the Institutional Review Board of the affiliated Hospital of Logistics University of Chinese People's Armed Police Forces on 2014. The animal protocol was approved by the Institutional Animal Care and Use Committee at the affiliated Hospital of Logistics University of Chinese People's Armed Police Forces.

\section{Animals and Groups}

The study was approved by the Committee on the Ethics of Animal Experiments of the University of Chinese People's Armed Police Forces, and performed in accordance with the Guide for the Care and Use of Laboratory Animals of the National Institutes of Health (Institute of Laboratory Animal Resources (U.S.) Committee on Care and Use of Laboratory Animals 2011). Thirty specific pathogen free male Sprague Dawley rats (weight: $360 \pm 10 \mathrm{~g}$ ) were purchased from the Beijing Weitong Lihua Experimental Animal Technology Co., Ltd. The rats were feed in separate cages of the animal room with the temperature of $20 \pm 3^{\circ} \mathrm{C}$ and humidity of $50 \pm 20 \%$. Fifty grams of total nutrient diet and plenty of clean drinking water were provided for these rats, receiving daily light for 12 hours. These rats were randomly divided into 3 groups: blank control group, TBI group and MSCs transplantation group for the treatment of TBI.

\section{Traumatic Brain Injury Rat Model}

The free fall device was used to establish brain trauma of the rats; a ball breaker with weight of $50 \mathrm{~g}$ was dropped from 90 $\mathrm{cm}$ height to form a free-fall strike, which resulted in closed cranio-cerebral trauma of rats. The pathological manifestations of traumatic brain injury were confirmed by hematoxylin and eosin (HE) histopathological staining observation.

\section{Cell Transfection}

Human embryonic kidney 293 T cells were cultured in $100 \mathrm{~mm}$ plate for 24 hours before transfection. Three auxiliary plasmids (Rev, $2.5 \mu \mathrm{g}$; VSVG, $3 \mu \mathrm{g}$; pMD, $5 \mu \mathrm{g}$ ) were added when cell density reached to $60 \%-70 \% .12 \mu \mathrm{g}$ lentivirus vector was used for transfection. After plasmid and 293T cells incubated for 16 hours, the transfection effect was observed by fluorescence microscope (Nikon E400, Nikon Instruments, Inc., Tokyo, Japan). Virus was harvested by $0.45 \mu \mathrm{m}$ filter after transfection for 24 hours. Filtered virus was concentrated in the PEG 6000 (GIBCO, Carlsbad, CA, USA) with final concentration of $8 \%$ - 
$10 \%$ in $4^{\circ} \mathrm{C}$ overnight, then centrifuged in $4^{\circ} \mathrm{C}$ at $1500 \mathrm{~g}$ for 45 minutes. The supernatant was discard, while the sediment cells were re-suspended with DMEM cell culture (GIBCO, Carlsbad, CA, USA), and then sterilized by $0.22 \mu \mathrm{m}$ filter. The concentrated virus was added into MSCs with $1 \mu$ polybrene. Cell medium was changed within 8 to 12 hours after infection. The CPE was observed under fluorescence microscopy 48 hours after infection.

\section{Transplantation of MSCs}

Rats were fixed in the stereotaxic apparatus (RWD 68001, RWD Life Science Co. Ltd, Shenzhen, China) and the operated ventricular coordinates were: 0 at bregma, $1.5 \mathrm{~mm}$ at lateral, $1.1 \mathrm{~mm}$ at behind, $4.5 \mathrm{~mm}$ in depth. A total of $1.5 \times 10^{6} \mathrm{MSCs}$ $(25 \mu \mathrm{l})$ was injected via ventricle. The needle was pulled out slowly after injection; the same volume physiological saline was injected in control groups.

\section{Hematoxylin Eosin (HE) Staining}

Briefly, sections were deparaffinized in xylene for 10 minutes twice and were re-hydrated in absolute alcohol for 5 minutes twice. Then sections were treated with 95\% alcohol for 2 minutes and $70 \%$ alcohol for 2 minutes. After being washed briefly in distilled water, they were stained in Harris hematoxylin solution (Sigma-Aldrich, St. Louis, MO, USA) for 8 minutes. The sections were washed in running tap water for 5 minutes, and differentiated in $1 \%$ acid alcohol for 30 seconds. They were then washed with running tap water for 1 minute, and blued in $0.2 \%$ ammonia water or saturated lithium carbonate solution for 30 seconds to 1 minute. They were washed in running tap water for 5 minutes, and rinsed in 95\% alcohol, 10 dips. Counterstain was conducted in eosin-phloxine solution for 30 seconds to 1 minute, before dehydration was used through 95\% alcohol, absolute alcohol for 5 minutes twice. The sections were finally cleared in xylene for 5 minutes twice and mounted with xylene based mounting medium (Polysciences, Inc. Warrington, PA, USA).

\section{Immunohistochemistry}

The rats were sacrificed by spinal dislocation methods on 10, 14 , and 20 days after transplantation of MSCs respectively. The brain tissue closed to the injury area was sampled, the thickness of each segment was about $5 \mathrm{~mm}$. The tissues were washed by PBS then were fixed with $4 \%$ paraformaldehyde. The tissues were embedded by paraffin, and sliced to sections with $5 \mu \mathrm{m}$ thickness. After dewaxing, sections were blocked with normal goat serum at room temperature for 20 minutes. Antibodies against green fluorescent protein or CD31/PECAM-1 (Endothelial Cell Marker) (Thermo fisher, Carlsbad, CA, USA) was added respectively and cultured at $4^{\circ} \mathrm{C}$ overnight; then washed by PBS, anti-IgG antibody labeled with biotin (Thermo fisher, Carlsbad, CA, USA) was added and cultured at $37^{\circ} \mathrm{C}$ for $20 \mathrm{~min}$, then washed by PBS. Streptavidin/HRP solution was added and cultured at $37^{\circ} \mathrm{C}$ for 20 minutes DAB Color Kit was used for coloring, and nucleus was stained by hematoxylin. Sections from each group were observed under optical microscope (Olympus CX6, Olympus, Tokyo, Japan).

\section{Statistical Analysis}

Data were presented as mean \pm SD and analyzed by SPSS 10.0 software (SPSS, Inc., Chicago, IL, USA). Each experiment was repeated at least three times. For each behavioral test, ANOVA was used to test the group effect by using repeated measures. Immunohistochemistry, and quantification of neurotrophic factors data were analyzed by Student's t-test. A $p$ value of less than 0.05 was considered statistically significant.

\section{RESULTS}

\section{Human UC-MSCs Preparation and Characterization}

The stem cells were cultured into the incubator, the change of culture solution was observed periodically and the solution by half amonut was changed every three days. The cells begin to seperate from the tissue in one week, and the confluence was up to $80 \%$ at day 10 (Figure $1 \mathrm{~A}-\mathrm{G}$ ). We then defined the isolation of MSCs by detecting CD 90, CD 73, CD 105 positive cells. Flow cytometry result demonstrated that, compared with 5 days of cell culture, the amount CD 90, CD 73, CD 105 positive cells in the MSC group showed a significant increase after 10 days of cell culture. Of note, a statistical decrease of CD 90, CD 73, CD 105 positive cells were found after 20 days of culture $(p<0.01)$ (Figure $1 A-G)$.

\section{UC-MSCs Labeled with Green Fluorescent Protein (GFP)}

In order to track the distribution of UC-MSCs, we constructed MSCs that stably express GFP protein. The lentivirus vector inserted with GFP was prepared for further transfection into MSCs. After transfection with GFP for 12 hours, 293T cells were observed by fluorescence (Figure 2A, B). Recombinant virus was propagated in $293 \mathrm{~T}$ cells and collected to infect MSCs. The fluorescence effect can be observed at 48 hours after MSCs were infected by GFP fusion tag lentiviral Vector (Figure 2C-F).

\section{Pathological Changes in Brain Tissue}

In control group, pathological changes showed that clear hyperemia, edema and obvious infiltration of inflammatory cells in brain tissue of rats with acute trauma brain injury (Figure 3A, C, E). However, with the treatment of MSCs, the brain injury was alleviated, and the infiltration of inflammatory cells also reduced obviously compared with the control group (Figure $3 B, D, F)$. The neurological severity scores were determined after the trauma for 10 days and the result also unraveled that the brain injury in the MSC group was mild compared to the control group ( ${ }^{*} \mathrm{p}<0.05$ ) (Figure $3 G$ ).

\section{MSC Distribution in the Brain}

To investigate the therapuetic effect of MSCs in trauma brain injury, we detected the distribution of MSCs by using immunohistochemical assay. Our data exhibited that the expression of GFP can be found both in the brain tissue and the area around the vessels after the injection (Figure 4AC). In addition, the enhancing expression of MVD was also observed in tissue after the treatment of MSCs for 10-15 days (Figure $5 \mathrm{~A}-\mathrm{C}$ ). We also observed the secretion of BDNF and glial fibrillary acidic protein (GFAP) after the therapy of MSCs. 
The immunofluorescence double staining result indicated that the expression of BDNF and GFAP in MSC group significantly increased, compared to that in control group $(p<0.05)$ (Figure $6 \mathrm{~A}-\mathrm{H})$.

\section{DISCUSSION}

The startling death rate of TBI has a major socioeconomic impact worldwide. In China, there are approximately 600,000 patients with traumatic brain injury every year, among which 100,000 are dead. The incidence of TBI in China also increases year by year on account for the rapid development of road traffic in China $(15,21,27)$. TBI includes two types in the view of pathology: limited and diffuse brain injuries. Diffuse brain injury is the main reason that causes non-hematoma, persistent coma or severe neurological dysfunction. Pioneering work found that the use of antagonist or scavengers reduced the mortality and disability rates and the brain was induced to produce endogenous brain-protecting factor after trauma brain injury, such as adenosine, heat shock protein, magnesium ions, etc., providing a basis for exploring the treatment method. Later on, study showed that the brain neurotransmitters and their receptors changed after TBI, and drugs that block or regulate the relative signaling pathway of

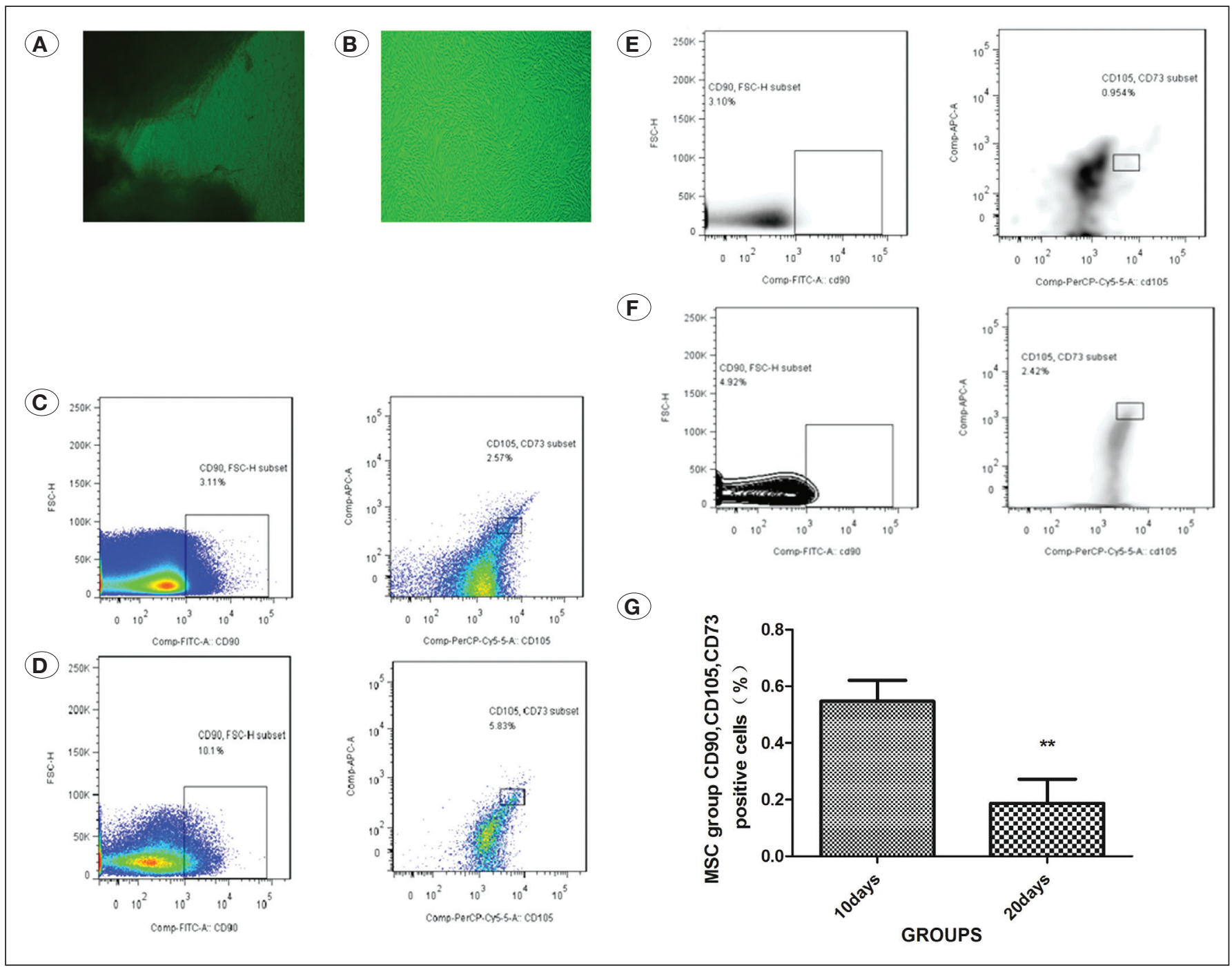

Figure 1: A) Human UC-MSCs preparation (40x). The human umbilical cord obtained from woman who gave birth was rinsed with PBS and the vascular was stripped. The Wharton's jelly was then stripped and was fully shredded into $1 \mathrm{~mm}$ in size followed by culturing them in the BioWhittaker ultra CULTURETM cell culture medium in an incubator at $37^{\circ} \mathrm{C}$ with $5 \% \mathrm{CO}$. A, The cells are spindle-shaped, and some can climb out of the Wharton's jelly; B, The cells are spindle-shaped with a whirlpool growth, and the confluence can be up to $80 \%$ after 10 days. B) The characterization of Human UC-MSCs. Cultured human UC-MSCs were identified through measuring the expressions of MSCs surface markers, CD90, CD73 and CD105 by low cytometry using FITC-labelled anti-CD90, APC-labelled antiCD73 and PerCP-labelled anti-CD105 antibodies. A) Control group after 10 days; B) - MSC group after 10 days; C) Control group after 20 days; D) MSC group after 20 days; E-G) Comparison of CD90, CD105, CD73 positive cells in MSC group after 10 days and 20 days $\left({ }^{\star \star} \mathrm{p}<0.01\right.$, compared with MSC group after 10 days). 

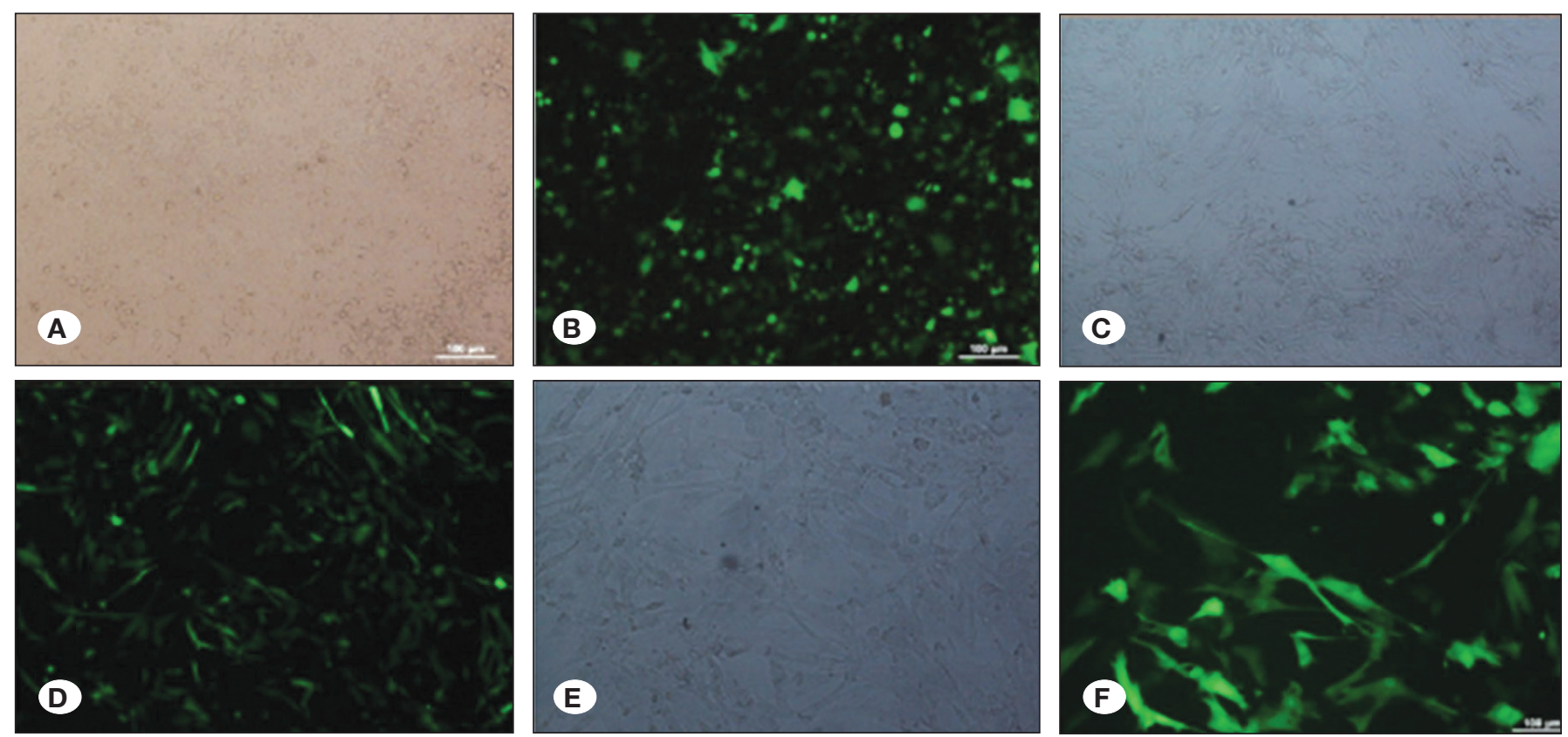

Figure 2: Morphology of the transfected 293T cells and MSCs. After transfection of GFP, the morphology of cells was observed under optical microscope and fluorescence microscope. A) 293T cells under optical microscope (x100); B) 293T cells under fluorescence microscope (x100); C) MSCs under optical microscope (x100); D) MSCs under fluorescence microscope (x100); E) MSCs under optical microscope (x200); F) MSCs under fluorescence microscope (x200).
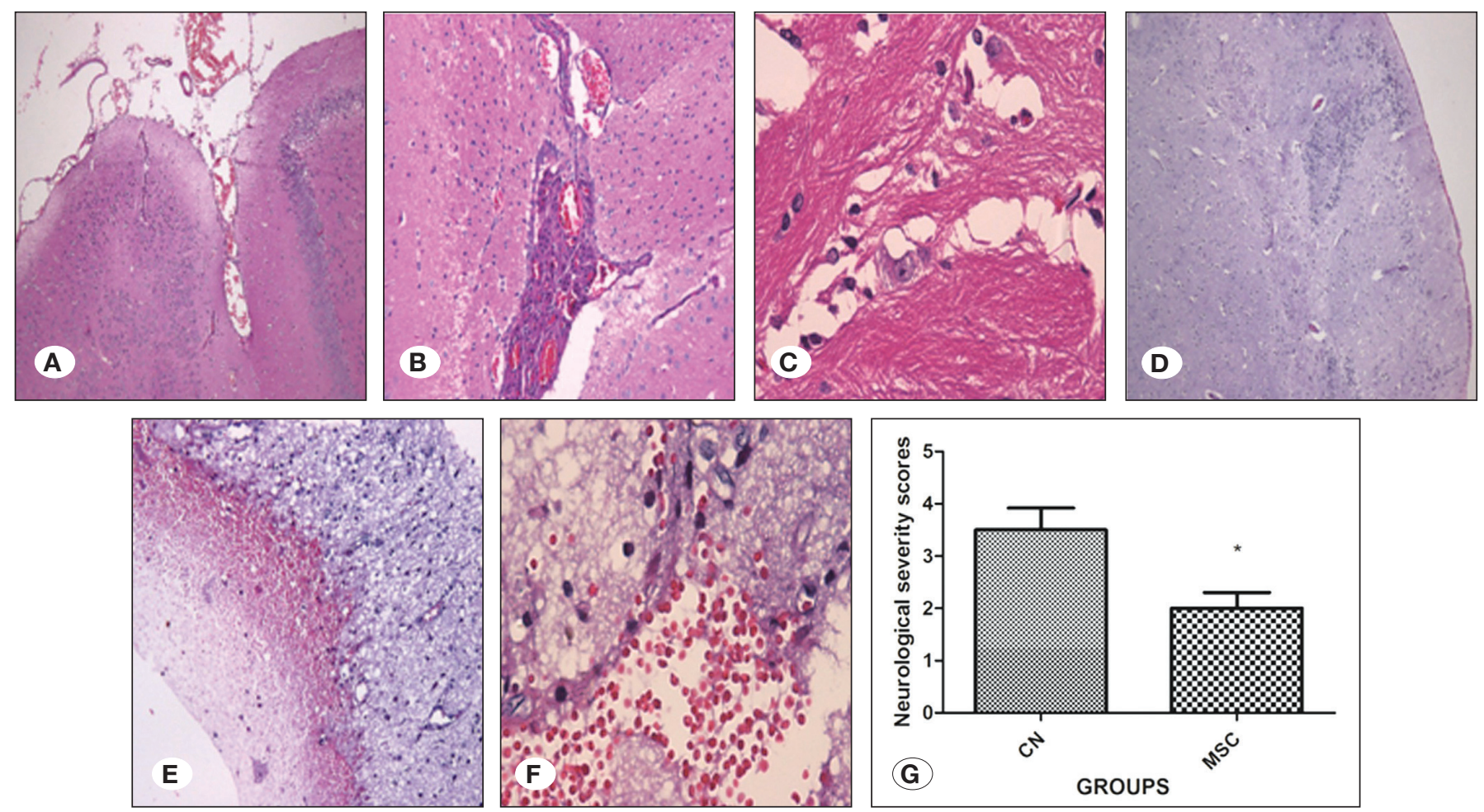

Figure 3: Pathological changes in brain tissue as assessed by HE staining. A-C) In MSC group, the morphology of the brain structure of each layer is normal, neurons of each level exist, the mesenchyme shows local edema; the subcortical, mesenchymal and intraventricular choroids plexus vessels show dilatation. D-F) In control group, neurons of each level exist. The subcortical vessels show dilatation and congestion; local mesenchymal vessels show congestion; hemorrhage with edema degeneration, and local infiltration of inflammatory cells is still visible. The brain injury was alleviated with reduced infiltrations of inflammatory cells in the MSC group compared with those in control group. G) The neurological severity score. After the trauma for 10 days, the neurological severity was determined. * $p<0.05$, compared to the CN (control) group. 
neurotransmitters had deeper curative effect on brain injury. In addition, the experimental study on the adult mammal found that the injured spinal cord neurons still remains the regeneration function, which therefore renewals the idea that the injured nerve cannot regenerate $(25,26,34)$.

As the development of stem cell technology and application in clinical practice, attractive findings in animal model exhibited that MSCs played a vital role in the treatment of central nervous system disease, such as brain injury, stroke and spinal cord injury (26). MSCs are adult stem cells which derive from the mesoderm and ectoderm and are widely present in many adult organs and connective tissues, such as bone marrow, fat, amniotic fluid, skeletal muscle, fetal lung, fetal liver, umbilical cord blood and umbilical cord

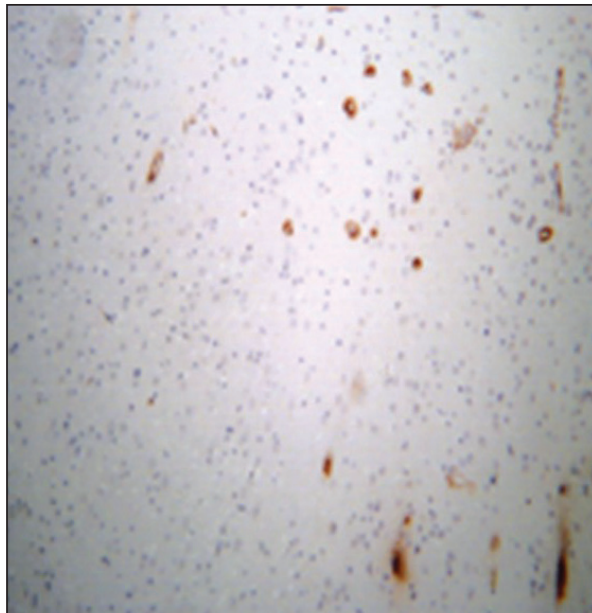

(A)
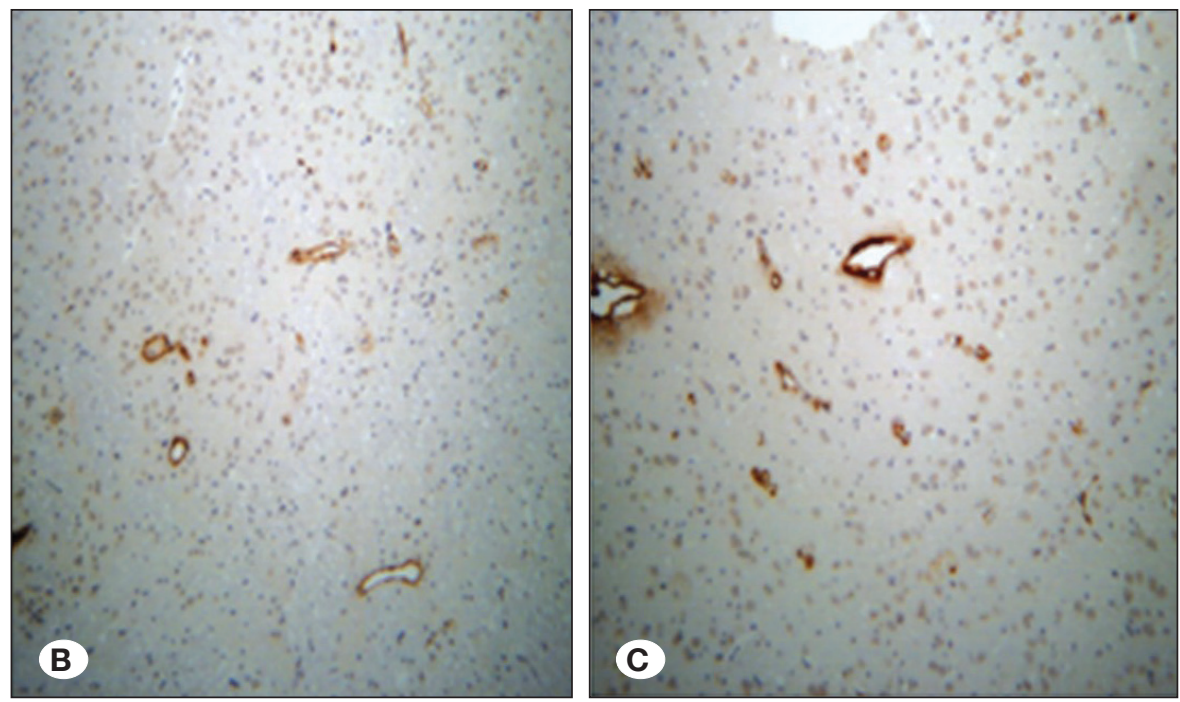

Figure 4: The distribution of MSCs in brain tissue. GFP expression was detected by by using immunohistochemical assay. The brain tissue closed to the injury area was collected and fixed with $4 \%$ paraformaldehyde followed by embedded by paraffin, and subsequent sliced to sections. After dewaxing, sections were blocked with normal goat serum followed by incubation with primary antibody against green fluorescent protein. After that, streptavidin/HRP solution was added and then DAB Color Kit was used for coloring, and nucleus was stained by hematoxylin. A) weakly positive GFP expression; B-C) strong positive GFP expression. The expression of GFP can be found both in the brain tissue and the area around the vessels, indicating transplanted MSCs with expression of GFP were accumulated in brain tissues.
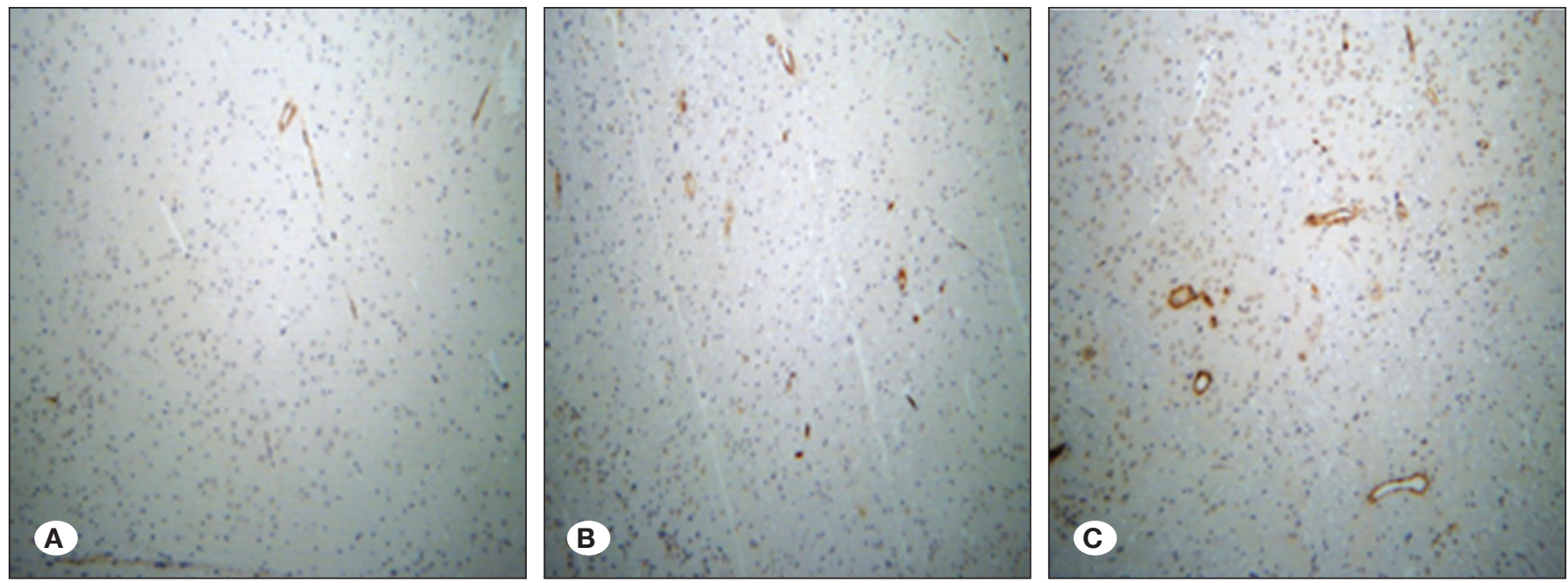

Figure 5: The distribution of MVD in the brain of each group animal. The brain tissue closed to the injury area was collected and fixed with $4 \%$ paraformaldehyde followed by embedded by paraffin, and subsequent sliced to sections. After dewaxing, sections were blocked with normal goat serum followed by incubation with primary antibody against CD31/PECAM-1 (Endothelial Cell Marker). After that, streptavidin/HRP solution was added and then DAB Color Kit was used for coloring, and nucleus was stained by hematoxylin. Control group (A), MSC group: strongly positive (B-10 $10^{\text {th }}$ day, $\mathbf{C}-14^{\text {th }}$ day); MVD of the MSC group acheives a significant increase compared with the control group $(p<0.05)$. 
$(2,18,19,27,29)$. The morphology of in vitro culture performs adherent growth, similar to that of fibroblasts. Under the certain induction, the cells can differentiate into mesodermderived osteoblasts, chondrocytes and adipocytes, and also liver cells, heart cells and nerve cells $(1-3,13,20,23,28,31,33)$. As demonstrated by in vitro studies, MSCs secrete various cell factors, for example, factor derived from matrix, hepatocyte growth factor, insulin-like growth factor, fibroblast growth factor, ischemia-induced factor, vascular endothelial growth factor, angiopoietin, monocyte chemotactic protein and interleukin so as to maintain the function of homeostasis, anti-inflammation and immunoregulation (4,24,32). Moreover, MSCs are widespread and easy to be isolated and cultured, together with low immune rejection, hence MSCs become a hotspot in the research of stem cell treatment. One of the crucial pathogenesis after brain injury is the damage of small and middle capillary network, which contains microcirculation disturbance and blood supply disorder. After mesenchymal
(A)

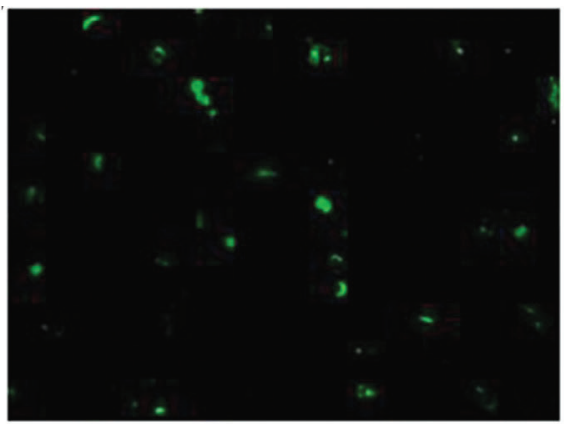

(B)

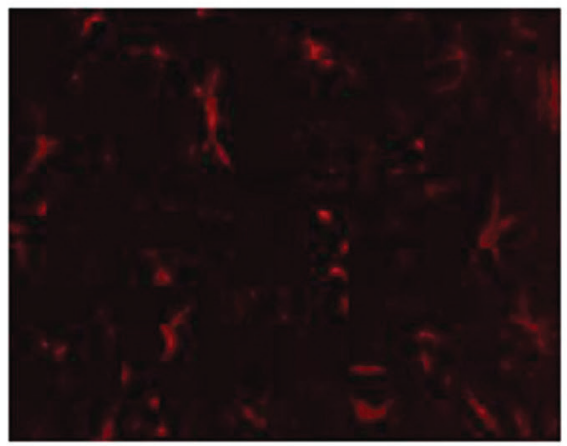

(C)

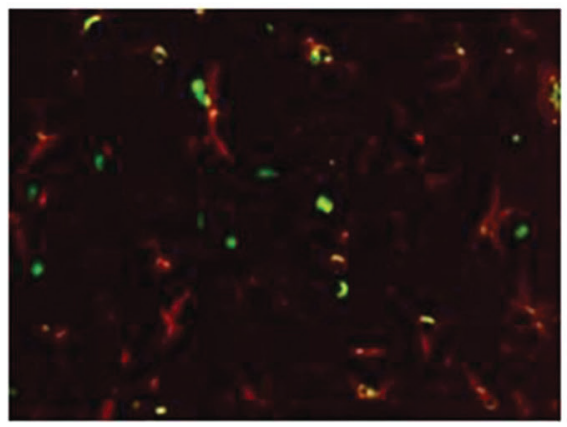

(G)

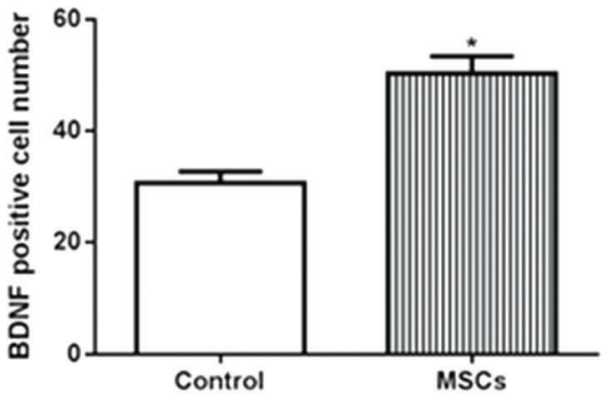

D

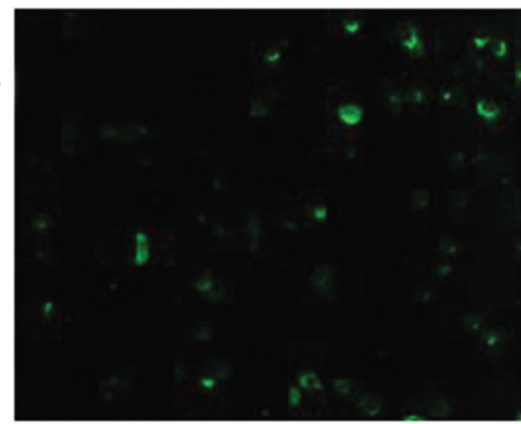

(E)

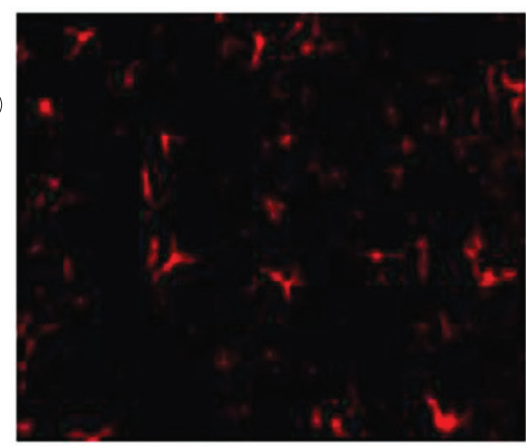

F

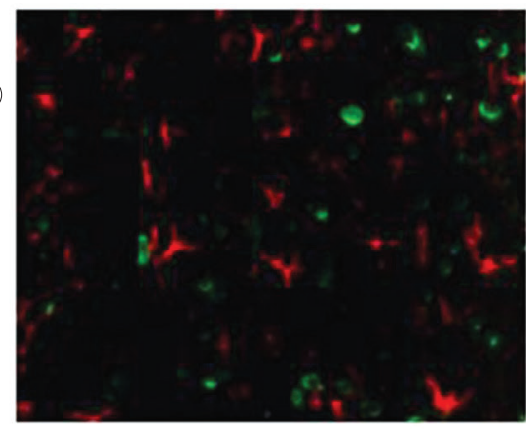

(H)

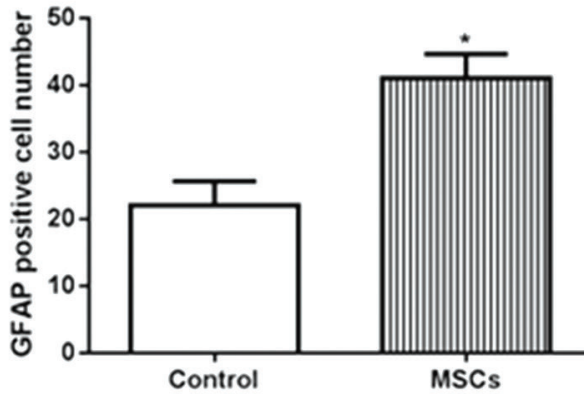

Figure 6: Distribution of BDNF, GFAP in the brain tissue of each group by immunofluorescence double staining technique. Brain extracted from rats was fixed in $4 \%$ paraformaldehyde and then dehydrated, waxed and sliced into $4 \mathrm{~mm}$ thickness followed by block with goat serum. Then, anti-BDNF and anti-GFAP antibody were added followed by addition of Alex Fluor 488-conjugated (for BDNF in green) and Alex Fluor 594-conjugated (for GFAP in red) sencondary antibody. At the endpoint, glycerol mounting was performed for confocal microscopy analysis (x40). Control group (A-C), MSC group: (D-F). A, D, GFAP staining; B, E, BDNF staining; $\mathbf{C}, \mathbf{F}, \mathrm{BDNF}$ and GFAP double-staining. Expression of BDNF and GFAP was quantified as the positive cell numbers and shown in $\mathbf{G}$ and $\mathbf{H}$. BDNF and GFAP of the MSC group acheives a significant increase compared with the control group $\left({ }^{*} p<0.05\right)$. 
stem cell transplantation, it exerts the immunomodulatory function via the secretion of autocrine and paracrine cytokines to promote angiogenesis in local ischemic tissue, while MSCs can integrate the damaged vascular plexus and then directly differentiate into mature new blood vessels $(8,9,16)$.

Recent progresses obtained further evidence about the treatment of human-derived mesenchymal stem cells for TBI and spinal cord injury, and survival rate was obviously improved, compared with non-treatment group. Our results also showed that the brain injury in rat with the treatment of MSCs was alleviated compared with the control group. Additionally, the expression of MVD, BDNF and GFAP in the tissue surrounding damaged brain was higher than that in the control group $(11,17,26,30)$. We therefore speculated that treatment with stem cells transplantation could effectively improve the blood supply around the damaged tissue, and was beneficial to the recovery of the damaged tissue. Our finding was also consistent with other studies that MSCs treatment on brain and spinal cord injury had significant effects and effectively improved the prognosis. Besides, the transplantation of the bone marrow MSCs for the treatment of brain injury in rats essentially increased the level of nerve growth factor and promoted the recovery of brain injury.

Evidence of xenogeneic transplantation in the rat model showed an obvious decrease of intimal hyperplasia, indicating that the injection of MSCs effectively improved the vein graft function. However, the efficacy of MSCs transplantation may vary due to the host age and different distribution of MSCs. In our study, the mesenchymal stem cell transplantation played a critical role in the recovery of injured area, particularly promoted the reconstruction of microcirculation, and fundamentally improved the nerve damage, although limitation in this study still exists that the treatment of MSCs in rats with different age has not yet been elucidated, multi-point, multiple injection and the correlation between rats weight and the amount of MSCs have not been determined.

\section{CONCLUSION}

Overall, our study presented here provides certain theoretical basis for further deep research on the MSCs to treat acute $\mathrm{TBI}$ and also proposes new challenges to the more precise therapy in the future.

\section{ACKNOWLEDGEMENTS}

This project was supported by Natural Science Foundation of China (No. 81801240); the CAMS Innovative Fund for Medical Science (Project no.2018-I2M-AI-012).

\section{REFERENCES}

1. Ankrum J, Karp JM: Mesenchymal stem cell therapy: Two steps forward, one step back. Trends Mol Med 16:203-209, 2010

2. Chan J, O'Donoghue K, de la Fuente J, Roberts IA, Kumar S, Morgan JE, Fisk NM: Human fetal mesenchymal stem cells as vehicles for gene delivery. Stem Cells 23:93-102, 2005
3. Choi M, Ban T, Rhim T: Therapeutic use of stem cell transplantation for cell replacement or cytoprotective effect of microvesicle released from mesenchymal stem cell. Mol Cells 37:133-139, 2014

4. Corcione A, Benvenuto F, Ferretti E, Giunti D, Cappiello V, Cazzanti F, Risso M, Gualandi F, Mancardi GL, Pistoia V, Uccelli A: Human mesenchymal stem cells modulate B-cell functions. Blood 107:367-372, 2006

5. Ding DC, Chang YH, Shyu WC, Lin SZ: Human umbilical cord mesenchymal stem cells: A new era for stem cell therapy. Cell Transplant 24:339-347, 2015

6. Dong H, Li G, Shang C, Yin H, Luo Y, Meng H, Li X, Wang Y, Lin L, Zhao M: Umbilical cord mesenchymal stem cell (UCMSC) transplantations for cerebral palsy. Am J Transl Res 10:901-906, 2018

7. Dong HJ, Li G, Meng HP, Shang CZ, Luo Y, Wen G, Zhao ML: How can Mesenchymal Stem Cells (MSCs) penetrate the blood brain barrier (BBB)? Turk Neurosurg 2018 (Epub ahead of print)

8. Dong HJ, Peng D, Zhao M, Wang L, Luo Y: Meeting prometheus: The mechanism of MSC-based therapies; cell replacement or "pretended bystander effects"? Turk Neurosurg 2018 (Epub ahead of print)

9. Dong HJ, Shang C, Li G, Luo YC, Yang Y, Lin L, Zhao ML: Differential protein expression in an acute disseminated myelitis patient after treatment with umbilical cord mesenchymal stem cells. Int J Clin Exp Med 10:7213-7219, 2017

10. El Omar R, Beroud J, Stoltz JF, Menu P, Velot E, Decot V: Umbilical cord mesenchymal stem cells: The new gold standard for mesenchymal stem cell-based therapies? Tissue Eng Part B Rev 20:523-544, 2014

11. Galindo LT, Filippo TR, Semedo P, Ariza CB, Moreira CM, Camara NO, Porcionatto MA: Mesenchymal stem cell therapy modulates the inflammatory response in experimental traumatic brain injury. Neurol Res Int 2011:1-9, 2011

12. Glennie S, Soeiro I, Dyson PJ, Lam EW, Dazzi F: Bone marrow mesenchymal stem cells induce division arrest anergy of activated T cells. Blood 105:2821-2827, 2005

13. Gokcinar-Yagci B, Uckan-Cetinkaya D, Celebi-Saltik B: Pericytes: Properties, functions and applications in tissue engineering. Stem Cell Rev 11:549-559, 2015

14. Gong W, Han Z, Zhao H, Wang Y, Wang J, Zhong J, Wang B, Wang S, Wang Y, Sun L, Han Z: Banking human umbilical cord-derived mesenchymal stromal cells for clinical use. Cell Transplant 21:207-216, 2012

15. Harting MT, Jimenez F, Xue H, Fischer UM, Baumgartner J, Dash PK, Cox CS: Intravenous mesenchymal stem cell therapy for traumatic brain injury. J Neurosurg 110:11891197, 2009

16. Huajiang D, Dingwei $P$, Yuechen L, Huipeng $M$, Rui $L$, Chongzhi S: The hope for pandoral's box: Mesenchymal stem cells (mscs) for promoting angiogenesis in stroke and trauma brain injury. Turkish Neurosurgery, 2018 (Epub ahead of print)

17. Jia Y, Shi X, Xie Y, Xie X, Wang Y, Li S: Human umbilical cord stem cell conditioned medium versus serum-free culture medium in the treatment of cryopreserved human ovarian tissues in in-vitro culture: A randomized controlled trial. Stem Cell Res Ther 8:152, 2017 
18. Karp JM, Leng Teo GS: Mesenchymal stem cell homing: The devil is in the details. Cell Stem Cell 4:206-216, 2009

19. Kim WS, Park BS, Sung JH, Yang JM, Park SB, Kwak SJ, Park JS: Wound healing effect of adipose-derived stem cells: A critical role of secretory factors on human dermal fibroblasts. J Dermatol Sci 48:15-24, 2007

20. Lee WS, Suzuki Y, Graves SS, Iwata M, Venkataraman GM, Mielcarek M, Peterson LJ, Ikehara S, Torok-Storb B, Storb $\mathrm{R}$ : Canine bone marrow-derived mesenchymal stromal cells suppress alloreactive lymphocyte proliferation in vitro but fail to enhance engraftment in canine bone marrow transplantation. Biol Blood Marrow Transplant 17:465-475, 2011

21. Li G, Yang Y, Dong HJ, Lin L: The research progress of mesenchymal stem cells in the treatment of traumatic brain injury. Turk Neurosurg 2017 (Epub ahead of print)

22. Li G, Zhang XA, Wang H, Wang X, Meng CL, Chan CY, Yew DT, Tsang KS, Li K, Tsai SN, Ngai SM, Han ZC, Lin MC, He ML, Kung HF: Comparative proteomic analysis of mesenchymal stem cells derived from human bone marrow, umbilical cord, and placenta: Implication in the migration. Proteomics 9:2030, 2009

23. Lou G, Chen Z, Zheng M, Liu Y: Mesenchymal stem cellderived exosomes as a new therapeutic strategy for liver diseases. Exp Mol Med 49:e346, 2017

24. Nagamura-Inoue $\mathrm{T}, \mathrm{He} \quad \mathrm{H}$ : Umbilical cord-derived mesenchymal stem cells: Their advantages and potential clinical utility. World J Stem Cells 6:195-202, 2014

25. Nichols JE, Niles JA, DeWitt D, Prough D, Parsley M, Vega S, Cantu A, Lee E, Cortiella J: Neurogenic and neuroprotective potential of a novel subpopulation of peripheral blood-derived CD133+ ABCG2+CXCR4+ mesenchymal stem cells: development of autologous cell-based therapeutics for traumatic brain injury. Stem Cell Res Ther 4:3, 2013
26. Qi L, Xue X, Sun J, Wu Q, Wang H, Guo Y, Sun B: The promising effects of transplanted umbilical cord mesenchymal stem cells on the treatment in traumatic brain injury. J Craniofac Surg 29:1689-1692, 2018

27. Qu C, Mahmood A, Lu D, Goussev A, Xiong Y, Chopp M: Treatment of traumatic brain injury in mice with marrow stromal cells. Brain Res 1208:234-239, 2008

28. Savukinas UB, Enes SR, Sjoland AA, Westergren-Thorsson G: Concise review: The bystander effect: Mesenchymal stem cell-mediated lung repair. Stem Cells 34:1437-1444, 2016

29. Sordi V: Mesenchymal stem cell homing capacity. Transplantation 87:S42-45, 2009

30. Sun L, Min L, Zhou H, Li M, Shao F, Wang W: Adolescent social isolation affects schizophrenia-like behavior and astrocyte biomarkers in the PFC of adult rats. Behav Brain Res 333:258-266, 2017

31. Uccelli A, Moretta L, Pistoia V: Mesenchymal stem cells in health and disease. Nat Rev Immunol 8:726-736, 2008

32. Wang LT, Ting CH, Yen ML, Liu KJ, Sytwu HK, Wu KK, Yen BL: Human mesenchymal stem cells (MSCs) for treatment towards immune- and inflammation-mediated diseases: Review of current clinical trials. J Biomed Sci 23:76, 2016

33. Zang L, Hao H, Liu J, Li Y, Han W, Mu Y: Mesenchymal stem cell therapy in type 2 diabetes mellitus. Diabetol Metab Syndr 9:36, 2017

34. Zhang Y, Chopp M, Meng Y, Katakowski M, Xin H, Mahmood A, Xiong Y: Effect of exosomes derived from multipluripotent mesenchymal stromal cells on functional recovery and neurovascular plasticity in rats after traumatic brain injury. $J$ Neurosurg 122:856-867, 2015 